\title{
Aplicação do método analytic hierarchy process (ahp) na priorização das ações de inovações em serviços em um estudo de multicaso
}

\section{Application of the analytic hierarchy process (ahp) method in the prioritization of innovation actions in services in a multi-case study}

\author{
Roger da Silva Wegner Doutorando, Universidade Federal de Santa Maria (UFSM), Brasil - \\ rswegnerr@gmail.com \\ Aline Battisti Graduanda, Universidade Federal de Santa Maria (UFSM), Brasil - \\ alinne.battisti@hotmail.com \\ Julia Tontini Mestranda, Universidade Federal de Santa Maria (UFSM), Brasil - ju- \\ tontini@hotmail.com \\ Michel Barboza Malheiros Mestrando, Universidade Federal de Santa Maria (UFSM), Brasil \\ - malheirosmb@gmail.com \\ Vanessa Piovesan Rossato Mestranda, Universidade Federal de Santa Maria (UFSM), Brasil \\ - vanessapiovesan@yahoo.com.br
}

\section{RESUMO}

Para alcançar maiores desempenhos junto ao setor de serviços ou em qualquer aspecto organizacional, é importante que ocorram mudanças constantes em busca de melhorias, e nisso se insere a inovação. Desta maneira, a realização de inovações vem a contribuir para o desempenho das organizações. Assim, a presente pesquisa teve como objetivo empregar o método AHP para melhor compreender as ações de inovações em um estudo de multicaso. Realizou-se a pesquisa na região norte do Rio Grande do Sul com três empresas de pequeno porte do setor de serviços (Academia, Boate e Provedora de internet), aplicando o método AHP para priorizar a tomada de decisão das empresas investigadas. Como resultado a Empresa " $A$ " priorizou a liderança e a cultura (25,96\%), a empresa " $B$ " destacou a liderança, aprendizagem organizacional e o marketing (19,43\%) e a Empresa " $C$ " priorizou a liderança e a aprendizagem organizacional (29,07\%). Diante destes resultados, as empresas podem verificar quais são os critérios que estão sendo destacados, mas, além disso, quais são aqueles que não estão recebendo a devida importância. Assim, é possível criar estratégias para melhorar os pontos mais fracos do negócio, gerando maiores resultados.

Palavras-chave: Inovação. Serviços. Processo decisório.

\begin{abstract}
In order to achieve greater performance in the service sector or in any organizational aspect, it is important that there be constant changes in the search for improvements, and this is where innovation is inserted. Innovation comes to contribute to the performance of organizations. Thus, the present research had as objective to use the AHP method to better understand the actions of innovation in a multi-case study. The research was carried out in the northern region of Rio Grande do Sul with three small services companies (a fitness gym, a nightclub and an internet provider), applying the AHP method to prioritize the decision-making of the companies investigated. As result company "A" prioritized leadership and culture (25.96\%), company "B" highlighted leadership, organizational learning and marketing (19.43\%) and company "C" prioritized leadership and organizational learning (29.07\%). Given these results, companies can check which criteria are being highlighted, but also which ones are not being given due importance. Thus, it is possible to create strategies to improve the weak points of the business, generating better results.
\end{abstract}

Keywords: Innovation. Services. Decision-making process. 


\section{INTRODUÇÃO}

No contexto econômico global, a realização de inovações é de crucial importância para as organizações. De uma maneira geral, esta é entendida como fundamental para a sobrevivência das micro e pequenas empresas, em um cenário cada vez mais competitivo. As micro e pequenas empresas juntas representam $27 \%$ do PIB brasileiro, estimando-se crescimento deste percentual com o passar dos anos. No setor de serviços, os pequenos negócios representam 36,3\% do PIB do Brasil (SEBRAE, 2014). Pesquisas realizadas na área da inovação tendem a apresentar a atual situação das organizações, visando compreender como estas empresas se comportam no mercado competitivo.

Diante do exposto, Deluca et al. (2017), desenvolveram um estudo com o objetivo de verificar a relação entre as capacidades inovativas, a diferenciação dos serviços e o desempenho das organizações. Esta pesquisa foi elaborada através de um estudo bibliográfico em relação às variáveis citadas, aplicada em supermercados do estado de Santa Catarina. Como resultados, foram obtidas a criação de dez proposições acerca destas variáveis, as quais se destacam: as capacidades inovativas têm relação positiva com desempenho; as capacidades inovativas têm relação positiva com diferenciação de serviços na dimensão dos processos e na dimensão de pessoas.

Outro estudo que vem a contemplar essa temática é o de Martins et al. (2016), o qual buscou analisar a gestão da inovação em uma cooperativa de grande porte atuante no setor de fabricação de alimentos. A metodologia utilizada pelos autores foi um estudo de caso e uma pesquisa de campo com a aplicação de questionários, o qual buscou verificar os aspectos relacionados ao processo de inovação na cooperativa estudada. Como resultado, ressalta-se que a cooperativa inovou em produtos e processos no período estudado, oportunizou espaço a seus funcionários na tomada de decisões, além de oferecer a eles capacitação profissional. Ficou evidente também, a valorização dos colaboradores, visto que os funcionários foram apontados como principais contribuintes do desenvolvimento das inovações.

Desta maneira, evidencia-se a importância dessa pesquisa, na intenção de buscar analisar as condições que fazem da inovação de serviços um diferencial, sendo que esta é muito significativa na determinação da competitividade entre as empresas em diferentes ramos. Assim, a presente pesquisa teve como objetivo, empregar o método AHP para melhor compreender as ações de inovações em um estudo de multicaso. Através dos dados obtidos, pretende-se gerar melhorias para as organizações em estudo, bem como, compreender a percepção dos gestores diante ao tema.

Justifica-se a importância da utilização do método AHP para encontrar resultados relevantes às organizações em estudo, e com isso analisar a prioridade dos critérios e subcritérios a fim de que essas mesmas venham a contribuir para o desempenho das organizações que prestam serviços. Desta forma, insere-se a seguinte questão do problema de pesquisa: O que faz da inovação no setor de serviços, um diferencial no processo de alavancagem da competitividade nas micro e pequenas empresas de um município do norte do Rio Grande do Sul?

O presente trabalho se estrutura da seguinte forma, introdução, referencial teórico, o qual contempla a invenção e inovação de produtos e processos e a inovação no setor de serviços. Aborda também metodologia, a qual utiliza a ferramenta AHP e, por fim os resultados e as considerações finais.

\section{REFERENCIAL TEÓRICO}

Nesta seção serão discutidos os assuntos referentes à invenção e inovação de produtos e processos e, também, a inovação no setor de serviços, objeto desse estudo. 


\subsection{Invenção e inovação em produtos ou processos}

Uma consideração importante a ser feita está relacionada à diferenciação entre invenção e inovação, conceitos estes que são confundidos com facilidade. A invenção é entendida pela criação de um processo, de uma técnica ou de um produto percebido como novo, que ainda não foi inserido ao mercado, mas que pode ser produzido ou comercializado (PACHECO, 2010). Já a inovação se introduz a partir da invenção de um produto novo, passa por um processo de desenvolvimento até chegar a sua comercialização, implicando no seu uso pela sociedade (FUCK; VILHA, 2012; PACHECO, 2010). Conforme a perspectiva de Santos (2003), não existe inovação sem invenção, uma acompanha a outra, transformando uma ideia em um fato concreto.

Ainda sobre o conceito de invenção, esta constitui apenas o começo de um processo com natureza de longo prazo, que tem como objetivo fazer com que uma ideia possa se expandir e se tornar útil. Nem sempre as invenções são aceitas pelo mercado ou se tornam sucesso de vendas. Uma invenção só se torna inovação a partir do momento que os consumidores se dispõem a comprá-la. Não interessa se a ideia é boa ou não, o público só vai aceitá-la, se for dado o devido valor à gestão do processo dentro das empresas, à gestão financeira e ao comportamento das organizações (TIDD; BESSANT, 2015).

Referente ao conceito de inovação, Chibás, Pantaleón e Rocha (2013) a consideram uma iniciativa que se manifesta como uma novidade para a organização e para o mercado e que, se aplicada de fato, traz resultados econômicos positivos para a empresa. Conforme o Manual de Oslo (OECD, 1997), eventuais melhorias nos processos produtivos podem levar ao desenvolvimento de novos produtos, e novas práticas organizacionais podem melhorar a capacidade da empresa de adquirir e criar novos conhecimentos e capacidades, que permitirão o desenvolvimento de outras inovações. Tidd e Bessant (2015) ressaltam que a inovação é essencialmente centrada em três fatores principais: geração de novas ideias, seleção das melhores e implementação. A geração de novas ideias pode surgir por meio da inspiração, das necessidades dos consumidores, das pesquisas e dos conhecimentos ou até mesmo da combinação de ideias já existentes. A seleção das melhores ideias necessita de experimentação para verificar quais são de fato as melhores ideias; a única maneira para sabermos se vale a pena desenvolvê-las é colocando-as em prática. A implementação ocorre quando esta simples ideia é transformada em um produto, serviço, ou processo acabado que os consumidores possam fazer uso.

Existem fatores que podem impossibilitar as atividades inovativas nas organizações. Segundo o Manual de Oslo (OECD, 1997), esses fatores podem ser econômicos, como os altos custos para inovar, ou a inexistência de demanda, fatores empresariais, como a falta de funcionários qualificados ou carentes de conhecimentos, e os fatores legais, como regulações e regras tributárias.

As inovações podem ocorrer em produtos ou em processos. No caso das inovações de produtos, estas permitem a utilização de novos conhecimentos ou tecnologias, ou baseiam-se em novas formas de utilização ou combinações de conhecimentos/tecnologias já existentes. O termo "produto" abrange tanto bens quanto serviços. As inovações de processos, estas referem-se às maneiras de funcionamento das tecnologias novas ou aperfeiçoadas, adquiridas pela implementação de novas técnicas de produção, e pelas maneiras diferenciadas ou alteradas de manipular e entregar os produtos ou serviços (OECD, 1997). Em respeito às inovações organizacionais, estas tratam das alterações que acontecem na estrutura gerencial da empresa em geral (TIGRE, 2006).

A inovação de produtos e processos podem ser gradativas, ou incrementais, de maneira que um produto já existente seja capaz de ser aperfeiçoado, através do aumento do seu desempenho (IBGE, 2011). No tocante às inovações radicais, estas dizem respeito à inserção de produtos, serviços ou processos completamente novos no mercado, sendo que estes estão estreitamente ligados às atividades de Pesquisa e Desenvolvimento (FUCK; VILHA, 2012). Segundo Tigre (2006) a inovação radical ultrapassa os limites da inovação incremental, ocasionando um salto da produção e introduzindo uma nova trajetória tecnológica.

Salienta-se que nesse processo da criação da inovação a partir da imersão de novos mercados, emerge o conceito de destruição criadora, caracterizada como a substituição de produtos antigos, por produtos que agregam mais valor aos clientes, alicerçada aos novos hábitos dos consumidores. Prospecta-se nesse cenário, obter desenvolvimento, configurado como elemento suplementar do capitalismo, à medida que novas 
técnicas, meios, tecnologias emergem, e a partir disso, conseguem alavancar a sua produtividade, propiciando vantagens competitivas.

Um dos principais desafios que permeiam os negócios inovadores é ter a capacidade de adaptar-se aos novos parâmetros, avaliando como reutilizar seus recursos disponíveis, a fim de manterem-se competitivos no mercado. Para tanto, os empreendedores precisam estar cientes das oscilações desse procedimento, uma vez que consiste em um trabalho incessante e constante da permuta de produtos deteriorados pelo valor econômico, por novos que agreguem mais significância aos consumidores. Nesse sentido, a teoria da destruição criadora, busca exemplificar que o capitalismo não é estático, e está suscetível a mudanças provocadas pelos empreendedores que implementam características inovadoras em seus produtos e serviços, impactando positivamente na economia (SCHUMPETER, 1982).

Portanto, como a destruição criadora, estuda as mudanças que fazem parte do sistema capitalista em prol das inovações, Schumpeter (1982) classifica 5 tipos de inovação que podem ser visualizadas no Quadro 1:

Quadro 1 - Tipos de inovação segundo Shumpeter

\begin{tabular}{|l|l|}
\hline \multicolumn{1}{|c|}{ Tipos de inovação } & \multicolumn{1}{c|}{ Caracterização } \\
\hline Introdução de um novo bem & $\begin{array}{l}\text { Introdução de um novo produto ou serviço, novo ou com valor } \\
\text { agregado que os consumidores não estejam familiarizados; }\end{array}$ \\
\hline $\begin{array}{l}\text { Introdução de um novo } \\
\text { método de produção }\end{array}$ & $\begin{array}{l}\text { Novo método de produção, ou ainda, diferentes maneiras de utilizar as } \\
\text { mercadorias; }\end{array}$ \\
\hline Abertura de um novo mercado & Abertura de um novo mercado que pode ter existido antes ou não; \\
\hline $\begin{array}{l}\text { Nova fonte de oferta de } \\
\text { matérias-primas ou de bens } \\
\text { semimanufaturados }\end{array}$ & Posição de monopólio; \\
\hline $\begin{array}{l}\text { Estabelecimento de uma nova } \\
\text { organização de qualquer } \\
\text { indústria }\end{array}$ & Criação da posição de monopólio. \\
\hline
\end{tabular}

Fonte: Adaptado de Schumpeter (1982).

O caminho da do sucesso inovador sugere que os empresários combinem as técnicas que sejam mais viáveis para o seu negócio. Esse procedimento decorre da habilidade dos gestores em reciclar os recursos disponíveis de maneira diferenciada, haja vista que propicia uma visão sistêmica e dinamista, deixando em evidência essas empresas no mercado.

\subsection{Inovações no setor de serviços}

O que caracteriza o setor de serviços é sua grande heterogeneidade em suas atividades, ele possui diferentes subsetores e estes se dividem em outros, com novas particularidades (JAKUBCIONIS; CARLSSON, 2018). Nos últimos anos o setor de serviços se destaca por seu desempenho e atuação na economia brasileira (IBGE, 2017). Em 2014, através da Pesquisa Anual de Serviços - PAS, obtida pelo Instituto Brasileiro de Geografia e Estatística (IBGE, 2014), estimou-se a existência de 1.332.260 empresas com atividade principal no setor de serviços, com $\mathrm{R} \$ 1,4$ trilhão obtidos em receita líquida, ocupando 13 milhões de indivíduos e pagando a estes, $\mathrm{R} \$ 289,7$ bilhões de reais em salários, retiradas ou diferentes outros tipos de remunerações.

Johnston e Huggins (2018) ressaltam através da análise realizada sobre o setor de serviços do Reino Unido que, em geral, em qualquer economia dominada pelos serviços, e com grande diversificação e variedade, tende a levar a um maior desenvolvimento de determinado local e região. Isso ocorre diante de maior geração de emprego e consequente mais demanda neste setor (IBGE, 2017).

Para alcançar maiores desempenhos junto ao setor de serviços ou em qualquer aspecto organizacional, é importante que ocorram mudanças constantes em busca de melhorias, e nisso se insere a inovação. Entretanto, como destaca Pinheiro et al. (2015), a inovação dentro do ambiente empresarial ainda 
não é uma constante e muito menos um elemento prioritário para os administradores, principalmente no que se refere às micro e pequenas empresas. Os autores destacam a importância de criar uma cultura inovadora e investimento em capacitações aos colaboradores.

Além disso, os primeiros trabalhos voltados às inovações em serviços resultaram na difusão de inovações tecnológicas, oriundas da indústria automobilística, através das criações de Ford (VARGAS, 2007). Com isso, a inserção da inovação neste setor se mostra essencial, pois gera maior produção e competitividade entre as empresas (BARATA, 2011), além dos resultados econômicos no mundo todo. Por outro lado, as características que diferenciam os produtos dos serviços, geram desafios e novas oportunidades às indústrias, pois, para se destacar, os serviços precisam possuir peculiaridades e diferenciais para que possam gerar maiores resultados (DAL BÓ et al., 2010).

Além disso, a inovação junto ao setor de serviços pode resultar em melhor atendimento das necessidades dos clientes; fácil contato de usuários e fornecedores; aumento da confiabilidade nos serviços; rápida produção e entrega do serviço; cumprimento de normas; e, aumento das prestações de serviços (TIGRE, 2006). Alcançar esses resultados não depende somente em incluir novas tecnologias de informação e comunicação no setor, mas as próprias mudanças nas organizações e processos produtivos.

Constata-se que a inovação tem papel fundamental no que se refere a maior vantagem competitiva entre as organizações, vistos os resultados que ela pode gerar (SILVA; BURGER, 2018). Essa inovação voltada ao setor de serviços, gera maior inclusão no mercado mundial e consequente mais desempenho (KINOSHITA, 2013). Entretanto, para alcançar esses resultados através da inovação, as empresas necessitam criar estratégias para alcançar o que almejam, e neste processo precisam tomar diferentes decisões. Nessa tomada de decisão, o método Analytic Hierarchy Process (AHP) pode auxiliar na identificação da melhor escolha a ser feita pela empresa. Na próxima seção se apresenta o delineamento do método AHP.

\subsection{Analytic Hierarchy Process (AHP)}

O método AHP (Analytic Hierarchy Process) foi, originalmente, desenvolvido pelo professor Thomas L. Saaty no início da década de 1970, sendo este um método multicritério mais utilizado e conhecido no apoio à tomada de decisões e na solução de conflitos, em problemas de múltiplos critérios (BAINHA; VIANNA; MEZA, 2018).

Assim, três princípios conduzem a resolução de problemas com a aplicação do AHP: a decomposição, julgamentos comparativos e síntese de prioridades (SAATY, 1990). Por meio destes princípios, o método AHP proporciona uma matemática objetiva para verificar as preferências subjetivas e pessoais de um determinado indivíduo ou grupo ao se tomar uma decisão (SAATY, 1991).

Para estabelecer a importância das preferências de cada critério, Saaty (1991) declara que para hierarquizar ou delinear as preferências torna-se essencial delinear, também, a importância de cada critério em relação a cada um dos outros critérios e, dentro de cada critério, a importância de cada alternativa com relação a cada uma das outras alternativas. Segundo o autor, esse processo é estruturado por meio de uma matriz quadrada de decisão, na qual os critérios e alternativas são comparadas par a par, seguida pela escala de comparação construída por Saaty (1991).

O referido método é essencial pois envolve a tomada de decisão e auxilia nas soluções de assuntos de ambientes complexos (SAATY, 1991; SELLITTO et al., 2012). Utilizando a técnica AHP é possível descrever por meio de forma ordenada as ações que se localizam no primeiro, segundo e terceiro plano e que fazem parte do processo decisivo.

Além disso, uma das grandes vantagens da utilização do método AHP é proporcionar que o usuário conceda pesos relativos para múltiplos critérios ou alternativas para um determinado critério, de modo intuitivo, na mesma frequência em que executa uma comparação par a par entre eles (SAATY, 1991). Com isso, o referido autor evidencia que mesmo quando duas variáveis são tidas como incomparáveis, levando em consideração os conhecimentos e a experiência dos indivíduos, é possível reconhecer qual dos critérios é o mais importante. 
Este modelo utiliza a composição de hierarquia para tornar mais simples os problemas que são complexos, como pode observar-se na Figura 1. Em um primeiro momento deve-se definir o objetivo, depois criar os critérios globais e específicos. Nesta pesquisa o número de níveis foi construído junto com as informações colhidas das empresas analisadas. Assim, foram conexas à diferenciação dos critérios que o próprio processo de desfragmentação oferece. E as matrizes, em que os inícios direcionam a força relativa ou o império de um componente em relação a outro.

Figura 1 - Estrutura hierárquica do problema

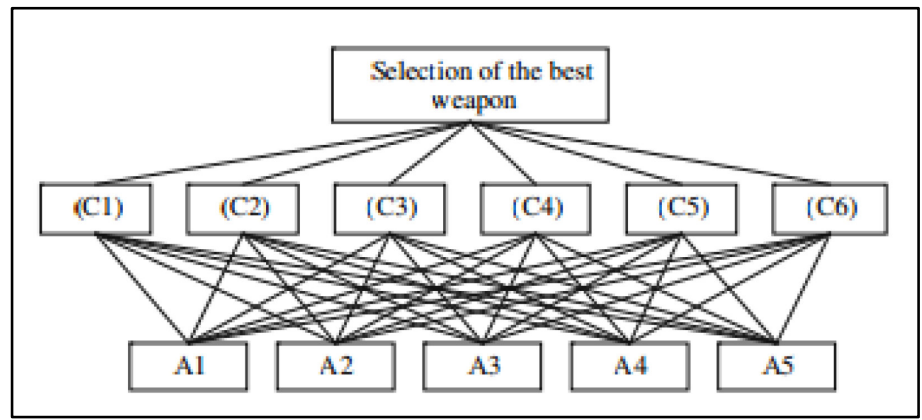

Fonte: Dağedeviren; Yavuz; Kılınc (2009).

Esse modelo busca priorizar os critérios e subcritérios mediante a percepção do julgador. 0 julgamento é realizado par a par conforme a escala de importância estudada por Saaty (1990), conforme a Tabela 1.

Tabela 1 - Escala de avaliação de AHP

\begin{tabular}{lll}
\hline ESCALA & AVALIAÇÃO & RECÍPROCO \\
\hline Extremamente preferido & 9 & $1 / 9$ \\
Muito forte a extremo & 8 & $1 / 8$ \\
Muito fortemente preferido & 7 & $1 / 7$ \\
Forte a muito forte & 6 & $1 / 6$ \\
Fortemente preferido & 5 & $1 / 5$ \\
Moderado a forte & 4 & $1 / 4$ \\
Moderadamente preferido & 3 & $1 / 3$ \\
lgual a moderado & 2 & $1 / 2$ \\
lgualmente preferido & 1 & 1 \\
\hline
\end{tabular}

Após o processo realizado, calcula-se o índice de consistência (IC) com o emprego do $\lambda_{\text {max }}$ obtido por: IC $=\left(\lambda_{\max }-n\right) /(n-1)$ e na formalização, calcula-se também a razão de consistência (RC) aplicando-se em: $\mathrm{CR}=\mathrm{IC} / \mathrm{IR}$. O índice randômico (IR) é obtido por meio de simulação e sintetizado na Tabela 2, e em geral, uma consistência que se pode aceitar é o RC $\leq 0,10$ (SAATY, 1991).

Tabela 2 - Índice randômico

\begin{tabular}{lllllllll}
\hline $\mathrm{n}$ & 3 & 4 & 5 & 6 & 7 & 8 & 9 & 10 \\
\hline $\mathrm{IR}$ & 0,58 & 0,9 & 1,12 & 1,24 & 1,32 & 1,41 & 1,45 & 1,49 \\
\hline
\end{tabular}

Fonte: Saaty (1991). 
Ao desenvolver estes cálculos é possível analisar a consistência do julgamento diante a percepção do julgador, notando se eles estão logicamente relacionados (SAATY, 2008).

\section{MATERIAIS E MÉTODOS}

A presente pesquisa objetivou empregar o método AHP para melhor compreender as ações de inovações em três empresas de pequeno porte do setor de serviços, localizadas na região norte do Rio Grande do Sul.

\subsection{Objeto de estudo}

A primeira empresa considerada foi uma academia, que atua no mercado competitivo há cinco anos e apresenta um quadro composto por oito funcionários. A organização apresenta duas áreas sendo, financeiro e o administrativo.

A segunda empresa é uma boate, que está no mercado há dois anos, e têm doze colaboradores, conta com três áreas sendo, marketing, financeiro e administrativo. Além destas, uma terceira organização trabalha no ramo de provedores de internet, onde atua há vinte anos no mercado e conta com um quadro de cinquenta e cinco trabalhadores, esta, apresenta quatro áreas sendo, financeiro, marketing, gestão de pessoas e o administrativo, atendendo mais de doze municípios da região.

A pesquisa apresenta um estudo de multicasos e se justifica pelo fato de analisar as ações inovadoras de três empresas diferentes. A abordagem do estudo é descritiva, pois busca descrever a percepção dos três gestores na intenção de identificar a prioridade das ações desenvolvidas diante do tema abordado. O estudo é também qualitativo, pois procurou entender a percepção dos gestores diante ao tema em estudo, através do método AHP.

\subsection{Procedimentos de Coleta de Dados}

Como técnica de coleta de dados utilizou-se um questionário estruturado com 26 questões voltadas à inovação no setor de serviços. Para as perguntas, utilizou-se da escala Likert, a qual estabelece que os entrevistados indiquem seu grau de concordância ou discordância (entre 1 e 5) de acordo com suas atitudes sobre um assunto, neste caso inovação.

Salienta-se que, conforme a perspectiva de Vargas (2006), o estudo do processo de inovação em serviços vem se mostrando como um elemento crucial no avanço das explicações da nova dinâmica entre os setores produtivos. Estes são protagonizados, em grande parte, pelos serviços que, mesmo nas atividades industriais, tem um papel fundamental na propagação do conhecimento e das inovações.

Após a aplicação do questionário com os gestores das três empresas analisadas, os dados foram tabulados em uma planilha no Software Microsoft Excelo. Em seguida, os dados foram analisados a partir do método Analytic Hierarchy Process (AHP).

\subsection{Procedimentos de Análise de Dados}

Para desenvolver esta pesquisa utilizou-se o método Analytic Hierarchy Process (AHP). Sendo que, este foi criado por Thomas L. Saaty, este é um método analítico, que permite realizar uma abordagem sistemática para resolver problemas complexos. O método AHP, prioriza a análise do julgador diante de um tema pesquisado, facilitando a tomada de decisões (SAATY; VARGAS, 1991; SAATY, 2008). Os passos utilizados com a aplicação do método AHP são comentadas nos próximos parágrafos.

A primeira etapa aborda a ideia da modelagem do problema. Aqui foi criada a estrutura do modelo hierárquico. Assim, na prática, primeiramente estabeleceu-se o objetivo geral, em seguida os critérios (vantagens obtidas por intermédio da inovação, liderança e inovação, cultura de inovação, aprendizagem 
organizacional, marketing e inovação, e os impactos esperados da inovação para o crescimento do negócio), buscando priorizar os critérios mediante a percepção dos gestores.

A segunda etapa, foi realizada às matrizes de comparação paritária entre os critérios e subcritérios, e foi possível identificar os vetores de prioridade global. Para cada critério foram apresentados três subcritérios. Verificou-se a combinação binária, com base na escala de importância de Saaty, a qual contempla 9 pontos e seus recíprocos. Os pesos 3, 5, 7 e 9 integram a ordem de grandeza para a comparação paritária, os pesos 2, 4, 6 e 8, consistem nos valores intermediários e o peso 1 apresenta a igualdade de importância. Por meio desses valores é possível realizar a comparação paritária dos critérios e subcritérios, assim foi possível construir as matrizes de comparação mediante a percepção dos gestores investigados.

A terceira etapa utilizada na pesquisa foi a análise, nesta verificou-se o julgamento, por meio do vetor de prioridade, onde foi possível analisar a prioridade dos critérios e subcritérios expostos e a sua consistência. $O$ índice de consistência da matriz $3 \times 3$ foi de 0,58 , isto se justifica pelo fato de que cada matriz é composta por três elementos, e de $6 \times 6$ foi de 1,24, esta matriz é composta de seis elementos. A extensão do método adota um erro até $10 \%$ de consistência.

Na quarta etapa foi feita a classificação dos critérios e subcritérios mediante análise global por meio do ranking para ocorrer a priorização conforme a opinião dos gestores, sendo as prioridades voltadas ao tema da inovação presente no setor de serviços. A Figura 2 apresenta a estrutura hierárquica do método em relação ao tema abordado.

Figura 2 - Estrutura hierárquica do AHP adaptada ao estudo

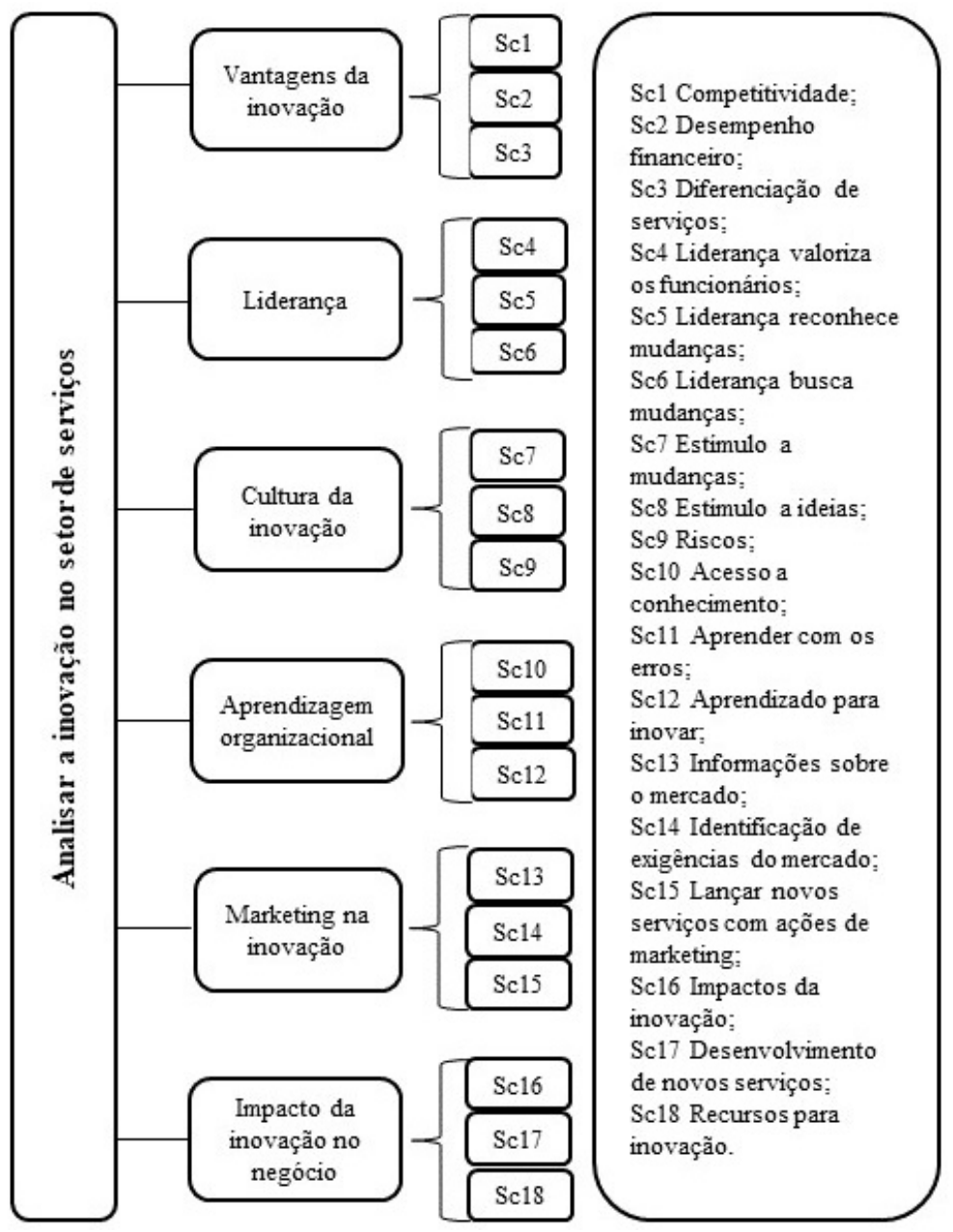

Fonte: elaborado pelos autores (2018).

$\mathrm{Na}$ estrutura hierárquica é possível visualizar o objetivo global, em seguida os critérios e seus subcritérios. Por meio do método AHP foi possível verificar o julgamento dos entrevistados e conhecer as 
prioridades de cada uma das organizações investigadas. Os dados foram mensurados por meio do software Microsoft ExcelO.

Foram criados para este estudo seis critérios, que serviram de base para compreender a inovação no setor de serviços. Os critérios foram: (C1) Vantagens da inovação; (C2) Liderança; (C3) Cultura da inovação; (C4) Aprendizagem organizacional; (C5) Marketing na inovação e (C6) Impacto da inovação no negócio. Para compreender melhor estes critérios, é possível verificar no Quadro 2 os seus conceitos.

Quadro 2 - Critérios e suas definições

\begin{tabular}{|l|l|}
\hline \multicolumn{1}{|c|}{ Critérios } & \multicolumn{1}{|c|}{ Conceito } \\
\hline C1 - Vantagens da inovação & $\begin{array}{l}\text { Análise e compreensão de mudanças no mercado para gerar } \\
\text { competitividade e crescer nos negócios, através de novidades para } \\
\text { os consumidores (FREITAS et al., 2017). }\end{array}$ \\
\hline C2 - Liderança & $\begin{array}{l}\text { É o conhecimento das aspirações e necessidades dos indivíduos, } \\
\text { pois cada um destes possui desejos, anseios e reações diferentes } \\
\text { (RUFFATTO, PAULl; FERRÃO, 2016). }\end{array}$ \\
\hline C3 - Cultura da inovação & $\begin{array}{l}\text { Construir um local de trabalho onde todos os colaboradores } \\
\text { busquem a inovação e esta esteja intrínseca em todas as atividades } \\
\text { realizadas (WOLF, 2015). }\end{array}$ \\
\hline C5 - Marketing na inovação & $\begin{array}{l}\text { Conjunto de conhecimento formado ao longo dos anos pelas } \\
\text { pessoas dentro da organização (GONZALEZ; CAMPOS, 2015). }\end{array}$ \\
\hline Utilização de estratégias de marketing nas inovações \\
organizacionais para gerar maior competitividade (GONÇALVE; \\
SUGAHARA, 2015).
\end{tabular}

Fonte: elaborado pelos autores (2018).

A inovação gera maiores resultados as organizações. De acordo com KON (2016), no setor de serviços ela pode aumentar ainda mais os benefícios, trazendo maior competitividade às empresas, visto ser um segmento mais intangível, porém, os desafios para isso são grandes.

\section{ANÁLISE E DISCUSSÃO DOS RESULTADOS}

Por meio da análise do método AHP foi possível verificar quais são os critérios e subcritérios que os gestores das Empresas A, B e C, têm como prioridade. Deste modo, será feita uma análise de cada empresa participante da pesquisa.

A Tabela 3 demonstra o julgamento do gestor da Empresa A (academia) frente aos critérios e subcritérios avaliados. 
Tabela 3 - Julgamento dos dados normalizados da empresa A

\begin{tabular}{|c|c|c|c|c|c|}
\hline Critérios & $\begin{array}{l}\text { Peso global } \\
\text { dos } \\
\text { Critérios }\end{array}$ & Subcritérios & $\begin{array}{l}\text { Peso local dos } \\
\text { subcritérios }\end{array}$ & $\begin{array}{l}\text { Peso global dos } \\
\text { subcritérios }\end{array}$ & $\begin{array}{l}\text { Classificação } \\
\text { de Prioridade }\end{array}$ \\
\hline \multirow{3}{*}{$\begin{array}{c}\text { CR1 } \\
\text { Vantagens }\end{array}$} & \multirow{3}{*}{$10,3912 \%$} & Scr1 & $18,8394 \%$ & 0,0196\% & 14 \\
\hline & & Scr2 & $8,0961 \%$ & $0,0084 \%$ & 15 \\
\hline & & Scr3 & $73,0645 \%$ & $0,0759 \%$ & 7 \\
\hline \multirow{3}{*}{$\begin{array}{c}\text { CR2 } \\
\text { Liderança }\end{array}$} & \multirow{3}{*}{$25,9577 \%$} & Scr4 & $42,8571 \%$ & $0,1112 \%$ & 3,5 \\
\hline & & Scr5 & $14,2857 \%$ & $0,0371 \%$ & 10 \\
\hline & & Scr6 & $42,8571 \%$ & $0,1112 \%$ & 3,5 \\
\hline \multirow{3}{*}{$\begin{array}{l}\text { CR3 } \\
\text { Cultura }\end{array}$} & \multirow{3}{*}{$25,9577 \%$} & Scr7 & $45,4545 \%$ & $0,1180 \%$ & 1,5 \\
\hline & & Scr8 & $45,4545 \%$ & $0,1180 \%$ & 1,5 \\
\hline & & Scr9 & $9,0909 \%$ & $0,0236 \%$ & 13 \\
\hline CR4 & \multirow{3}{*}{$21,6146 \%$} & Scr10 & $14,2857 \%$ & $0,0309 \%$ & 11 \\
\hline \multirow{3}{*}{$\begin{array}{l}\text { Aprendizagem } \\
\text { Organizacional }\end{array}$} & & Scr11 & $42,8571 \%$ & $0,0926 \%$ & 5,5 \\
\hline & & Scr12 & $42,8571 \%$ & $0,0926 \%$ & 5,5 \\
\hline & \multirow{3}{*}{$12,4792 \%$} & Scr13 & $6,6667 \%$ & $0,0083 \%$ & 16 \\
\hline \multirow{2}{*}{$\begin{array}{c}\text { CR5 } \\
\text { Marketing }\end{array}$} & & Scr14 & $46,6667 \%$ & $0,0582 \%$ & 8,5 \\
\hline & & Scr15 & $46,6667 \%$ & $0,0582 \%$ & 8,5 \\
\hline \multirow{3}{*}{$\begin{array}{c}\text { CR6 } \\
\text { Impactos } \\
\text { causados }\end{array}$} & \multirow{3}{*}{$3,5996 \%$} & Scr16 & $71,4286 \%$ & $0,0257 \%$ & 12 \\
\hline & & Scr17 & $14,2857 \%$ & $0,0051 \%$ & 17,5 \\
\hline & & Scr18 & $14,2857 \%$ & $0,0051 \%$ & 17,5 \\
\hline
\end{tabular}

$\mathrm{O} C r 2$ e Cr3 "Liderança" e "Cultura", respectivamente, alcançaram o maior grau de importância perante os demais. Entende-se por liderança, o conhecimento das aspirações e necessidades dos indivíduos (RUFFATTO, PAULI; FERRÃO, 2016). Por meio destes construtos destacados, notou-se que a empresa visa direcionar seus esforços na liderança a fim de influenciar os colaboradores a desenvolver inovações nos serviços. A cultura organizacional alinhada com as ações de inovação aumenta o desempenho da organização em termos de produtividade. O gestor da empresa investigada destaca que a criação de uma cultura direcionada a inovação é essencial para o futuro do empreendimento, pois o ambiente organizacional deve estar favorável à agilidade na tomada de decisão e desenvolver equipes multidisciplinares capazes de apresentar soluções vinculadas a temas de futuro.

No que diz respeito à análise realizada em relação aos subcritérios locais, percebe-se que no $\mathrm{Cr} 2$ destacou-se o Scr4 e Scr6, ambos com o mesmo valor (42,8571\%), estes referem-se às perguntas: "a liderança valoriza os funcionários criativos e empreendedores" e, "a liderança busca mudanças na organização". Diante dos dados destacados, verificou-se que o gestor busca valorizar as ações criativas e empreendedoras por parte da equipe, buscando oferecer aos seus clientes serviços que apresentem um diferencial em termos de qualidade e experiência. Outro ponto priorizado pelo mesmo, é busca pela mudança constante, o gestor entende que os clientes buscam novas experiências nos serviços oferecidos, assim, torna-se necessários a equipe oferecer um atendimento com qualidade diferenciada, proporcionado aos clientes experiências memoráveis.

No $\mathrm{Cr} 1$ que indica o critério "Vantagens obtidas pela empresa por intermédio da inovação" obteve destaque o subcritério Scr3 que se refere à diferenciação de produtos e serviços. Esta diferenciação tem por objetivo influenciar a concorrência entre as empresas, aumentando assim, o tamanho das barreiras à entrada. O gestor compreende que a inovação provoca ganhos em termos de produtividade para o seu negócio. A inovação diante da percepção do gestor permite que a sua organização consiga se diferenciar dos demais correntes, além disso, abre novas oportunidades de negócio e resultada ganho para todos os envolvidos. 
Já o Cr3 os subcritérios que foram priorizados foram Scr7 e Scr8 $(45,4545 \%)$ estes se referem em "as pessoas são estimuladas a sugerirem novas ideias referentes aos serviços desenvolvidos" e "a empresa permite que, para a busca de novas soluções sejam assumidos riscos". O gestor destaca que os colaboradores são estimulados a desenvolver novas ideias capazes de solucionar problemas e melhorar a qualidade dos serviços. Além disso, salienta que empresa busca se diferenciar em relação à ampla concorrência, assumindo riscos diante das suas tomadas de decisões.

O Cr4, obteve 21,6146\% de importância, e como subcritérios desta variável, destacam-se o Scr11 e Scr12, os quais ambos demonstraram um valor de 42,8571\%. Este destaca que a empresa é capaz de aprender a partir dos seus erros e dos equívocos de outras organizações, e que a empresa está sempre buscando aprendizado para inovar. Diante dessas variáveis destacadas, notou-se que a empresa busca alinhar o conhecimento com a inovação. O gestor entende que o conhecimento desenvolvido pelos colaboradores é capaz de resolver problemas e promover ganhos para o empreendimento, além disso, o conhecimento e a inovação oferece a oportunidade de novos aprendizados.

No critério "Marketing", Cr5, destacam-se os Scr14 e Scr15, (ambos com grau de 46,6667\%), os quais referem-se "à capacidade da empresa em identificar e analisar as exigências de seus clientes e de seus possíveis clientes" e "capacidade da empresa lançar novos produtos empregando ações de marketing". O gestor compreende que a organização necessita entender as necessidades e os desejos que os clientes possuem em relação aos serviços ofertados, apontando que são desenvolvidas pesquisas de satisfação na organização investigada. Outra variável destacada, associa-se a ideia de desenvolver novos serviços empregando ações de marketing. Assim, a empresa busca oferecer diversos planos alinhados aos serviços ofertando e utiliza as redes sociais, jornal e rádio para divulgar as mesmas.

O Cr6 que representa os "Impactos esperados da inovação para o crescimento do negócio" obteve o menor grau, dentre os critérios analisados. Destacou o Scr16 (71,4286\%), este se refere à questão "as inovações de produtos e/ou processos nos últimos 5 anos impactaram a empresa melhorando a qualidade dos produtos". O gestor está trabalhando fortemente na inovação de seus serviços. No último ano, a empresa buscou parcerias com outros profissionais de áreas complementares, como resultado, hoje a academia oferece também serviços voltados à nutrição alimentar e serviços direcionados a fisioterapia.

Mediante a análise global é possível entender por meio do ranking quais são as ações que o gestor vem priorizando. Assim, percebe-se que as prioridades estão voltadas nos critérios de: Liderança (2), Cultura (3) e Aprendizagem Organizacional (4). E os subcritérios com maior destaque foram: Scr7 - A empresa estimula que os funcionários invistam parte do seu tempo planejando mudanças e o Scr8 - as pessoas são estimuladas a sugerirem novas ideias para os serviços. Diante desses resultados notou-se que esta empresa vem trabalhando as ações de inovação com o objetivo de estimular os colaboradores a alinhar as suas ideias junto com o objetivo da organização, visando assim, um melhor posicionamento diante do mercado competitivo. Deste modo, pode se perceber que a inovação para esta organização está ligada com a liderança, cultura e a aprendizagem organizacional.

Tabela 4 - Índice de consistência das matrizes da empresa A

\begin{tabular}{|c|c|c|c|}
\hline Critérios & $\begin{array}{c}\text { Peso global dos } \\
\text { Critérios }\end{array}$ & Subcritérios & Peso local dos subcritérios \\
\hline \multirow{3}{*}{$\begin{array}{c}\text { CR1 } \\
\text { Vantagens }\end{array}$} & \multirow{9}{*}{$\begin{array}{c}\lambda \mathrm{MAX}= \\
6,235056 \\
\mathrm{IC}=0,047011 \\
\mathrm{RC}=0,03791\end{array}$} & Scr1 & $\lambda \mathrm{MAX}=3,064888$ \\
\hline & & Scr2 & $I C=0,032444$ \\
\hline & & Scr3 & $\mathrm{RC}=0,05594$ \\
\hline \multirow{3}{*}{$\begin{array}{c}\text { CR2 } \\
\text { Liderança }\end{array}$} & & Scr4 & $\lambda \mathrm{MAX}=3$ \\
\hline & & Scr5 & $\mathrm{IC}=0$ \\
\hline & & Scr6 & $\mathrm{RC}=0,0000$ \\
\hline \multirow{3}{*}{$\begin{array}{c}\text { CR3 } \\
\text { Cultura }\end{array}$} & & Scr7 & $\lambda \mathrm{MAX}=3$ \\
\hline & & Scr8 & $\mathrm{IC}=4,44$ \\
\hline & & Scr9 & $\mathrm{RC}=0,000$ \\
\hline
\end{tabular}




\begin{tabular}{|c|c|c|}
\hline \multirow{3}{*}{$\begin{array}{c}\text { CR4 } \\
\text { Aprendizagem } \\
\text { Organizacional }\end{array}$} & Scr10 & \multirow{2}{*}{$\begin{array}{c}\lambda \mathrm{MAX}=3 \\
\mathrm{IC}=0\end{array}$} \\
\hline & Scr11 & \\
\hline & Scr12 & $\mathrm{RC}=0,0000$ \\
\hline \multirow{3}{*}{$\begin{array}{c}\text { CR5 } \\
\text { Marketing }\end{array}$} & Scr13 & \multirow{3}{*}{$\begin{array}{c}\lambda \mathrm{MAX}=3 \\
\mathrm{IC}=0 \\
\mathrm{RC}=0,0000\end{array}$} \\
\hline & Scr14 & \\
\hline & Scr15 & \\
\hline \multirow{3}{*}{$\begin{array}{c}\text { CR6 } \\
\text { Impactos } \\
\text { causados }\end{array}$} & Scr16 & \multirow{3}{*}{$\begin{array}{c}\lambda M A X=3 \\
I C=0 \\
R C=0,0000\end{array}$} \\
\hline & Scr17 & \\
\hline & Scr18 & \\
\hline
\end{tabular}

Fonte: elaborado pelos autores (2018).

De acordo com a literatura apresentada por Saaty, o CR da matriz julgada deve ser menor ou igual 0,10. Desta forma, é possível notar na Tabela 4 que o julgamento dado pelo gestor da empresa $A$ foi consistente, pois todos os critérios e subcritérios são menores que 0,10 .

Diante destes resultados, foi realizado o julgamento do gestor da Empresa B (boate) frente os critérios e subcritérios avaliados sendo demonstrados na Tabela 3.

Tabela 5 - Julgamento dos dados normalizados da empresa B

\begin{tabular}{|c|c|c|c|c|c|}
\hline Critérios & $\begin{array}{l}\text { Peso global } \\
\text { dos } \\
\text { Critérios }\end{array}$ & Subcritérios & $\begin{array}{l}\text { Peso local dos } \\
\text { subcritérios }\end{array}$ & $\begin{array}{l}\text { Peso global } \\
\text { dos } \\
\text { subcritérios }\end{array}$ & $\begin{array}{l}\text { Classificação } \\
\text { de Prioridade }\end{array}$ \\
\hline \multirow{4}{*}{$\begin{array}{c}\text { CR1 } \\
\text { Vantagens }\end{array}$} & \multirow{4}{*}{$9,3420 \%$} & Scr1 & $60,0000 \%$ & $0,0561 \%$ & 11 \\
\hline & & Scr2 & $20,0000 \%$ & $0,0187 \%$ & 15,5 \\
\hline & & Scr3 & $20,0000 \%$ & $0,0187 \%$ & 15,5 \\
\hline & & Scr4 & $14,2800 \%$ & $0,0277 \%$ & 13,5 \\
\hline \multirow{2}{*}{$\begin{array}{c}\text { CR2 } \\
\text { Liderança }\end{array}$} & \multirow[t]{3}{*}{$19,4321 \%$} & Scr5 & $42,8500 \%$ & $0,0833 \%$ & 3,5 \\
\hline & & Scr6 & $42,8500 \%$ & $0,0833 \%$ & 3,5 \\
\hline \multirow{3}{*}{$\begin{array}{l}\text { CR3 } \\
\text { Cultura }\end{array}$} & & Scr7 & $10,4700 \%$ & $0,0169 \%$ & 17 \\
\hline & \multirow[t]{2}{*}{$16,1808 \%$} & Scr8 & $63,6900 \%$ & $0,1031 \%$ & 1 \\
\hline & & Scr9 & $25,8200 \%$ & $0,0418 \%$ & 12 \\
\hline CR4 & & Scr10 & $14,2800 \%$ & $0,0277 \%$ & 13,5 \\
\hline \multirow{3}{*}{$\begin{array}{l}\text { Aprendizagem } \\
\text { Organizacional }\end{array}$} & \multirow[t]{3}{*}{$19,4321 \%$} & Scr11 & $42,8500 \%$ & $0,0833 \%$ & 3,5 \\
\hline & & Scr12 & $42,8500 \%$ & $0,0833 \%$ & 3,5 \\
\hline & & Scr13 & $33,3300 \%$ & $0,0648 \%$ & 9 \\
\hline \multirow{2}{*}{$\begin{array}{c}\text { CR5 } \\
\text { Marketing }\end{array}$} & \multirow[t]{2}{*}{$19,4321 \%$} & Scr14 & $33,3300 \%$ & $0,0648 \%$ & 9 \\
\hline & & Scr15 & $33,3300 \%$ & $0,0648 \%$ & 9 \\
\hline \multirow{3}{*}{$\begin{array}{c}\text { CR6 } \\
\text { Impactos } \\
\text { causados }\end{array}$} & \multirow{3}{*}{$16,1808 \%$} & Scr16 & $46,6600 \%$ & $0,0755 \%$ & 6,5 \\
\hline & & Scr17 & $6,6600 \%$ & $0,0108 \%$ & 18 \\
\hline & & Scr18 & $46,6600 \%$ & $0,0755 \%$ & 6,5 \\
\hline
\end{tabular}

Fonte: elaborado pelos autores (2018).

$\mathrm{O} \mathrm{Cr} 2, \mathrm{Cr} 4$ e $\mathrm{Cr} 5$, "Liderança", "Aprendizagem Organizacional" e "Marketing", respectivamente, apresentaram o mesmo grau de importância, sendo também o grau mais elevado perante os demais $(19,4321 \%)$. O gestor da empresa retrata que a inovação é a chave para se obter o sucesso atualmente e, cada vez mais, esta variável se torna um elemento importante que diferencia a sua organização das demais. Ter um líder que saiba influenciar a sua equipe a desenvolver a inovação em suas atividades é fundamental para que a organização realize suas estratégias e alcance os objetivos estabelecidos. 
O gestor acredita que a inovação é percebida como o fruto de um processo de aprendizagem, que visa gerar e aplicar novos conhecimentos em procedimentos e processos operacionais e estratégicos. Por fim, outro elemento que contribui fortemente com este tema é o marketing, o gestor relata que inovação deve ser empregada nos serviços oferecidos, a fim de, atender as necessidades e os desejos dos clientes.

No Cr2, o Scr5 e Scr6 apresentaram o mesmo grau, (42,8500\%), estes referem-se às alternativas: "a liderança reconhece que mudanças são importantes para o futuro da empresa", e "a liderança busca mudanças na organização". O gestor acredita que a gestão de mudança tem como objetivo auxiliar a organização na execução das atividades tácitas, operacionais e estratégicas. Assim, torna-se necessário que o líder esteja alinhado com a sua equipe, garantindo que a inovação esteja presente nas ações desenvolvidas.

No $\mathrm{Cr} 4$, os subcritérios que se destacaram, foram o Scr11 e Scr12, ambos com o mesmo grau de importância (42,8500\%), os quais se referiam às questões: "a empresa é capaz de aprender a partir dos seus erros e de outras organizações", e "a empresa busca aprendizado para inovar". Inovação é percebida nesta organização como um meio de aprendizagem, o gestor salienta que o erro traz conhecimento. A organização busca constantemente estimular os colaboradores a buscar o conhecimento com a intenção de aplicar este nas atividades desenvolvidas.

Em relação Cr5, este demonstrou seus subcritérios, Scr13, Scr14 e Scr15, com o mesmo grau de importância (33,3300\%), que se referem a "empresa coletar informações sobre mudanças de mercado", "a empresa analisar as exigências dos clientes" e "a empresa lanças novos serviços empregando ações de marketing". Diante dos dados apontados nota-se que o gestor desta empresa busca compreender as exigências dos clientes objetivando oferecer serviços com a qualidade almejada. Assim, a empresa trabalha fortemente com marketing, buscando oferecer aos clientes experiências satisfatórias.

O Cr1 obteve o menor grau de importância se comparado aos demais, apresentando 9,3420\%, e como subcritério desta variável, destacou-se o Scr1, o qual demonstrou valor exato de $60 \%$. Este subcritério destacou que a empresa acredita que a inovação gera uma elevação da competitividade entre as organizações. O gestor compreende que a inovação é um fator diferencial que vem a fortalecer o desempenho da organização diante de seus concorrentes.

O Cr3 e Cr6 que representam "Cultura" e "Impactos esperados da inovação para o crescimento do negócio" obtiveram grau intermediário em relação aos demais critérios, ambos apresentaram o mesmo grau, sendo (16,1808\%). Se tratando da análise realizada em relação aos subcritérios locais, percebe-se que no $\mathrm{Cr} 3$ destacou-se o Scr8 com o maior valor dentre os demais, com o valor de 63,6900\%, este refere-se à pergunta: as pessoas são estimuladas a sugerirem novas ideias para produtos (bens ou serviços) ou processos? A liderança busca estimular a sua equipe em trazer novas ideias para melhorar os serviços, deste modo, o gestor acredita que a percepção de melhoria produzida pela sua equipe pode contribuir fortemente nas atividades desenvolvidas.

E no Cr6 foi o Scr16 e Scr17 (46,6600), estes se referem a "empregar inovação nos últimos 5 anos impactara qualidade nos serviços" e a "empresa possui recursos para empreender em inovações". A empresa em estudo vem buscando empregar a inovação, seu foco está voltado às necessidades dos clientes. Assim, a organização vem produzindo diferentes festas com alta tecnologia, buscando proporcionar aos seus clientes experiências memoráveis.

Por meio de uma análise geral, pode-se perceber por meio do ranking quais são as ações que o gestor da Empresa B prioriza, desta maneira, nota-se que as prioridades estão voltadas a questões de: Liderança (1), Aprendizagem organizacional (4) e Marketing (5), e o subcritério como maior destaque foi Scr8 - as pessoas são estimuladas a sugerirem novas ideias para os serviços. O gestor busca em seus colaboradores ideias que venham a contribuir para o seu negócio, a união da equipe é fundamental para se obter os objetivos estabelecidos. Assim, a inovação para esta empresa está alinhada com a liderança, aprendizagem organizacional e o marketing voltado às necessidades e desejos dos clientes. 
Tabela 6 - Índice de consistência das matrizes da empresa B

\begin{tabular}{|c|c|c|c|}
\hline Critérios & $\begin{array}{l}\text { Peso global } \\
\text { dos Critérios }\end{array}$ & Subcritérios & Peso local dos subcritérios \\
\hline \multirow{3}{*}{$\begin{array}{c}\text { CR1 } \\
\text { Vantagens }\end{array}$} & \multirow{18}{*}{$\begin{array}{c}\lambda \mathrm{MAX}=6,6467 \\
\mathrm{IC}=0,1293 \\
\mathrm{RC}=0,1043\end{array}$} & Scr1 & $\lambda M A X=3$ \\
\hline & & Scr2 & $\mathrm{IC}=0$ \\
\hline & & Scr3 & $\mathrm{RC}=0,0000$ \\
\hline \multirow{3}{*}{$\begin{array}{c}\text { CR2 } \\
\text { Liderança }\end{array}$} & & Scr4 & $\lambda M A X=3$ \\
\hline & & Scr5 & $\mathrm{IC}=0$ \\
\hline & & Scr6 & $\mathrm{RC}=0,0000$ \\
\hline \multirow{3}{*}{$\begin{array}{l}\text { CR3 } \\
\text { Cultura }\end{array}$} & & Scr7 & $\lambda \mathrm{MAX}=3.0385$ \\
\hline & & Scr8 & $\mathrm{IC}=0,0192$ \\
\hline & & Scr9 & $\mathrm{RC}=0,03320$ \\
\hline \multirow{3}{*}{$\begin{array}{c}\text { CR4 } \\
\text { Aprendizagem } \\
\text { Organizacional }\end{array}$} & & Scr10 & $\lambda M A X=3$ \\
\hline & & Scr11 & $\mathrm{IC}=0$ \\
\hline & & Scr12 & $\mathrm{RC}=0,0000$ \\
\hline \multirow{3}{*}{$\begin{array}{c}\text { CR5 } \\
\text { Marketing }\end{array}$} & & Scr13 & $\lambda \mathrm{MAX}=3$ \\
\hline & & Scr14 & $\mathrm{IC}=0$ \\
\hline & & Scr15 & $\mathrm{RC}=0,0000$ \\
\hline \multirow{3}{*}{$\begin{array}{c}\text { CR6 } \\
\text { Impactos } \\
\text { causados }\end{array}$} & & Scr16 & $\lambda M A X=3$ \\
\hline & & Scr17 & $I C=0$ \\
\hline & & Scr18 & $R C=0,0000$ \\
\hline
\end{tabular}

Fonte: elaborado pelos autores (2018).

Por meio dos dados apresentados na Tabela 6, é possível perceber que o julgamento paritário realizado com o gestor da empresa B é consistente, pois o CR de todos os critérios e subcritérios foram menores que 0,10 .

Diante disso, foi realizado o julgamento do gestor da Empresa C (empresa provedora de internet), frente aos critérios e subcritérios avaliados, para poder identificar as prioridades que organização considera relevante, esses dados podem ser visualizados na Tabela 5.

Tabela 7 - Julgamento dos dados normalizados da empresa C

\begin{tabular}{|c|c|c|c|c|c|}
\hline Critérios & $\begin{array}{l}\text { Peso global } \\
\text { dos Critérios }\end{array}$ & Subcritérios & Peso local dos subcritérios & $\begin{array}{c}\text { Peso global } \\
\text { dos } \\
\text { subcritérios }\end{array}$ & $\begin{array}{c}\text { Classificação de } \\
\text { Prioridade }\end{array}$ \\
\hline \multirow{3}{*}{$\begin{array}{c}\text { CR1 } \\
\text { Vantagens }\end{array}$} & \multirow{3}{*}{$16,7839 \%$} & Scr1 & $42,8500 \%$ & $0,0719 \%$ & 7,5 \\
\hline & & Scr2 & $42,8500 \%$ & $0,0719 \%$ & 7,5 \\
\hline & & Scr3 & $14,2800 \%$ & $0,0240 \%$ & 11 \\
\hline \multirow{3}{*}{$\begin{array}{c}\text { CR2 } \\
\text { Liderança }\end{array}$} & \multirow{3}{*}{$29,0706 \%$} & Scr4 & $33,3300 \%$ & $0,0969 \%$ & 3,5 \\
\hline & & Scr5 & $33,3300 \%$ & $0,0969 \%$ & 3,5 \\
\hline & & Scr6 & $33,3300 \%$ & $0,0969 \%$ & 3,5 \\
\hline \multirow{3}{*}{$\begin{array}{c}\text { CR3 } \\
\text { Cultura }\end{array}$} & \multirow{3}{*}{$6,7188 \%$} & Scr7 & $25,8200 \%$ & $0,0173 \%$ & 17 \\
\hline & & Scr8 & $63,6900 \%$ & $0,0428 \%$ & 10 \\
\hline & & Scr9 & $10,4700 \%$ & $0,0070 \%$ & 18 \\
\hline \multirow{3}{*}{$\begin{array}{c}\text { CR4 } \\
\text { Aprendizagem } \\
\text { Organizacional }\end{array}$} & \multirow{3}{*}{$29,0706 \%$} & Scr10 & $33,3300 \%$ & $0,0969 \%$ & 3,5 \\
\hline & & Scr11 & $33,3300 \%$ & $0,0969 \%$ & 3,5 \\
\hline & & Scr12 & $33,3300 \%$ & $0,0969 \%$ & 3,5 \\
\hline
\end{tabular}




\begin{tabular}{cccccc} 
& & & $\mathbf{6 0 , 0 0 0 0} \%$ & $0,0698 \%$ & \multicolumn{1}{c}{ Scr13 } \\
CR5 & $11,6373 \%$ & Scr14 & $20,0000 \%$ & $0,0233 \%$ & 12,5 \\
Marketing & & Scr15 & $20,0000 \%$ & $0,0233 \%$ & 12,5 \\
& & Scr16 & $\mathbf{0 , 3 3 3 3 0 0}$ & $0,0224 \%$ & 15 \\
CR6 & & Scr17 & $\mathbf{0 , 3 3 3 3 0 0}$ & $0,0224 \%$ & 15 \\
Impactos & $6,7188 \%$ & Scr18 & $\mathbf{0 , 3 3 3 3 0 0}$ & $0,0224 \%$ & 15 \\
\hline
\end{tabular}

Fonte: elaborado pelos autores (2018).

O Cr2 e Cr4 "Liderança" e "Aprendizagem Organizacional", respectivamente, obtiveram o maior grau de importância perante os demais, estes apresentaram grau de 29,0706\%. A aprendizagem organizacional exerce papel de grande relevância, sendo que a elevação da capacidade competitiva, em um cenário exigente, torna a aprendizagem organizacional uma grande necessidade e diferencial (CAMPOS; MEDEIROS; MELO, 2018).

De acordo com a percepção do gestor a aprendizagem organizacional e a liderança são dois elementos fundamentais que se ligam com as ações de inovação. A liderança nesta organização direciona seus esforços para estimular a sua equipe a desenvolver atividades que contemplam a inovação, o objetivo da empresa é ofertar serviços com qualidade e um diferencial em relação à ampla concorrência.

Em relação Cr2 percebe-se que os Scr4, Scr5 e Scr6 apresentaram o mesmo grau (0.333300) de prioridade, estes referem-se "a importância dada pela liderança à valorização dos funcionários", "ao reconhecimento de que mudanças são necessárias" e "a busca por mudanças na organização". O gestor valoriza o desempenho de seus colaboradores, buscando também estimular as mudanças nas atividades, pois por meio destas ações é possível promover a inovação.

Em relação ao Cr4, os que se destacaram os Scr10, Scr11, Scr12 $(33,3300)$ que correspondem à ideia de "acesso ao conhecimento", "aprender com os erros" e "aprendizado para inovar". A organização priorizou igualitariamente as três variáveis que correspondem à aprendizagem organizacional. O gestor relatou que a aprendizagem organizacional é ponto-chave para desenvolver ações de inovações, a organização busca e aplica o conhecimento nas atividades realizadas.

O Cr1 obteve (16,7839\%) de importância, e como subcritérios desta variável, destacam-se o Scr1 e Scr2, os quais ambos demonstraram um valor de (42,8500\%). Que destaca que "a inovação traz como vantagens à empresa, a elevação da competitividade" e "a melhoria no desempenho financeiro da mesma". O gestor retratou que a inovação é um fator determinante para o aumento da competitividade, além de auxiliar no desempenho financeiro da empresa.

O Cr3 e o Cr6 que representam "Cultura" e "Impactos esperados da inovação para o crescimento do negócio", obtiveram o menor grau de importância, dentre os critérios analisados, demonstrando um valor de (6,7188\%). No Cr3 destacou-se o Scr8 (0,636900\%), este se refere "se as pessoas são estimuladas a sugerirem novas ideias para produtos ou processos". A empresa em estudo busca incentivar os seus colaboradores a expor suas ideias a fim de melhorar os serviços oferecidos.

Analisando os dados da Tabela 7, é possível compreender por meio do ranking quais são as ações que o gestor da Empresa C (provedora de internet) mais priorizou. Assim, percebe-se que as prioridades estão voltadas a questões de: Vantagens obtidas pela empresa por intermédio da inovação (1), Liderança (2) e Aprendizagem Organizacional (4). Os subcritérios com maior destaque foram: Scr4 - a liderança valoriza os funcionários criativos e empreendedores, Scr5 - a liderança reconhece que mudanças são importantes para o futuro da empresa, Scr6 - a liderança busca mudanças na organização, Scr10 - a empresa fornece a seus funcionários acesso ao conhecimento necessário à realização de algo novo, Scr11 - a empresa é capaz de aprender a partir dos seus erros e de outras organizações e o Scr12 - a empresa busca aprendizado para inovar. Assim, a inovação para esta empresa está alinhada com a liderança e a aprendizagem organizacional. 
Tabela 8 - Índice de consistência das matrizes da empresa C

\begin{tabular}{|c|c|c|c|}
\hline Critérios & $\begin{array}{l}\text { Peso global dos } \\
\text { Critérios }\end{array}$ & Subcritérios & Peso local dos subcritérios \\
\hline \multirow{3}{*}{$\begin{array}{c}\text { CR1 } \\
\text { Vantagens }\end{array}$} & \multirow{18}{*}{$\begin{array}{c}\lambda \mathrm{MAX}=6,4033 \\
\mathrm{IC}=0,0806 \\
\mathrm{RC}=0,0650\end{array}$} & Scr1 & $\lambda M A X=3$ \\
\hline & & Scr2 & $I C=4,44$ \\
\hline & & Scr3 & $\mathrm{RC}=0,0000$ \\
\hline \multirow{3}{*}{$\begin{array}{c}\text { CR2 } \\
\text { Liderança }\end{array}$} & & Scr4 & $\lambda \mathrm{MAX}=3$ \\
\hline & & Scr5 & $\mathrm{IC}=0$ \\
\hline & & Scr6 & $\mathrm{RC}=0,0000$ \\
\hline \multirow{3}{*}{$\begin{array}{c}\text { CR3 } \\
\text { Cultura }\end{array}$} & & Scr7 & $\lambda \mathrm{MAX}=3,0385$ \\
\hline & & Scr8 & $\mathrm{IC}=0,0192$ \\
\hline & & Scr9 & $\mathrm{RC}=0,03320$ \\
\hline \multirow{3}{*}{$\begin{array}{l}\text { CR4 } \\
\text { Aprendizagem } \\
\text { Organizacional }\end{array}$} & & Scr10 & $\lambda \mathrm{MAX}=3$ \\
\hline & & Scr11 & $\mathrm{IC}=0$ \\
\hline & & Scr12 & $\mathrm{RC}=0,0000$ \\
\hline \multirow{3}{*}{$\begin{array}{c}\text { CR5 } \\
\text { Marketing }\end{array}$} & & Scr13 & $\lambda M A X=3$ \\
\hline & & Scr14 & $\mathrm{IC}=0$ \\
\hline & & Scr15 & $\mathrm{RC}=0,0000$ \\
\hline \multirow{3}{*}{$\begin{array}{c}\text { CR6 } \\
\text { Impactos } \\
\text { causados }\end{array}$} & & Scr16 & $\lambda \mathrm{MAX}=3$ \\
\hline & & Scr17 & $\mathrm{IC}=0$ \\
\hline & & Scr18 & $\mathrm{RC}=0,0000$ \\
\hline
\end{tabular}

De acordo com Saaty, o CR da matriz analisadas deve ser menor ou igual 0,10. Assim, é possível visualizar que na Tabela 8 que os julgamentos referentes à empresa $C$, dos critérios e subcritérios são menores que 0,10 , assim considerados consistentes de acordo com a literatura.

\section{CONSIDERAÇÕES FINAIS}

Através da utilização do método AHP, o presente estudo teve por objetivo analisar a inovação em serviços de três empresas localizadas no norte do estado do Rio Grande do Sul. As empresas escolhidas são de ramos diferentes, o que leva a uma análise distinta referente ao tema proposto, em busca de identificar os fatores decisivos voltados à inovação nestas empresas. As empresas estudadas foram uma academia (A), uma boate (B) e a terceira uma empresa provedora de internet (C).

Após as análises realizadas através do método $\mathrm{AHP}$, observou-se que na empresa " $\mathrm{A}$ ", o gestor prioriza os critérios "liderança" e "cultura". No que diz respeito aos subcritérios, os mais destacados foram o "Scr7", que salienta o estímulo da empresa para que os funcionários invistam parte do seu tempo planejando mudanças e, O "Scr8" que afirma que as pessoas são estimuladas a sugerirem novas ideias para os serviços. Para estas matrizes abordadas, todos os RC foram menores de 10\%, destacando-se como consistentes.

Quanto a empresas " $\mathrm{B}$ ", os critérios salientados pelos gestores foram a "liderança", "aprendizagem organizacional" e "marketing", apresentando mesmo valor de priorização. Já o subcritério mais destacado foi o "Scr8", onde afirma que as pessoas são estimuladas a sugerir novas ideias para os serviços.

Por fim, quanto aos resultados da empresa " $\mathrm{C}$ " destacaram-se os critérios "liderança" e "aprendizagem organizacional". Sobre os subcritérios, os mais salientados foram o "Scr4" - a liderança valoriza os funcionários criativos e empreendedores, "Scr5" - a liderança reconhece que mudanças são importantes para o futuro da empresa, "Scr6" - a liderança busca mudanças na organização, "Scr10" - a empresa fornece a seus funcionários acesso ao conhecimento necessário à realização de algo novo, "Scr11" - a empresa é capaz de aprender a partir 
dos seus erros e de outras organizações e o "Scr12" - a empresa busca aprendizado para inovar. Todas as variáveis apresentaram valores de RC conforme o método, sendo menores de $10 \%$.

Destaca-se a partir de uma análise geral que, as três empresas priorizam a liderança como um fator essencial para a gestão da empresa. Isso, em partes, se deve ao fator de os gestores serem os respondentes da pesquisa. Por outro lado, as empresas acreditam que para a inovação no negócio, a liderança é um fator essencial a ser trabalhado.

Além da liderança, é válido destacar que as empresas estudadas possuem suas particularidades, visto através dos resultados. A empresa " $A$ " prioriza a cultura, a " $B$ " "aprendizagem organizacional" e "marketing" $e_{\text {, }}$ a "C" "aprendizagem organizacional". Isso ocorre, devido aos objetivos que cada uma busca, também pela área de atuação diferente.

Sobre os subcritérios mais priorizados, o que mais se destacou entre as empresas foi o Sc8, que aponta a importância de as pessoas serem estimuladas a sugerir novas ideias para os serviços. Isso contribui para que as inovações em serviços sejam realizadas por todos aqueles que estão envolvidos na empresa.

Diante disso, compreende-se a importância da utilização do método AHP para o processo de identificação de fatores que os gestores priorizam em suas empresas. Com isso, estas empresas podem verificar quais são os critérios que estão sendo destacados, mas além disso, quais são aqueles que não estão recebendo a devida importância. Assim, é possível criar estratégias para melhorar os pontos mais fracos do negócio, gerando maiores resultados.

Como limitações encontradas no estudo, está a não utilização da opinião dos colaboradores das empresas, restringindo-se aos gestores. Para estudos futuros, sugere-se a utilização do método na análise da opinião dos gestores e dos funcionários de uma empresa, confrontando as opiniões obtidas e analisando essas diferenças.

\section{REFERÊNCIAS}

BAINHA, F. S. A.; VIANNA, D. S.; MEZA, E. B. M. Aplicação do Método AHP à Tomada de Decisão Gerencial: um estudo de caso em serviço de hotelaria offshore. Marketing \& Tourism Review, Belo Horizonte, v. 3, n. 2, p. 1-40, 2018.

BARATA, J. M. M. Inovação nos Serviços: Conceitos, Modelos e Medidas. Uma Aplicação ao Sector Bancário, Instituto Superior de Economia e Gestão. Teaching Economics Working Papers Universidade Técnica de Lisboa, Lisboa, p. 1-58, 2011.

CAMPOS, I. M. S.; MEDEIROS, J. W. M.; MELO, M. S. M. Comunidade de Prática (CoP) e Aprendizagem Organizacional no Contexto da Gestão de Pessoas na Universidade Federal da Paraíba (UFPB). NAVUS Revista de Gestão e Tecnologia, v. 8, n. 2, p. 17-26, 2018.

CAMPOS, M. G.; SANTOS, D. F. L.; DONADON, F. A. B. Impacto dos investimentos em inovação na indústria brasileira. Revista Gestão Industrial, Ponta Grossa, v. 13, n. 3, p. 13-36, set./nov. 2017.

CHIBÁS, F. O.; PANTALEÓN, E. M.; ROCHA, T. A. Gestão da Inovação e da criatividade hoje: apontes e reflexões. Holos, v. 3, p. 15-26, ago. 2013.

DAĞEDEVIREN, M.; YAVUZ, S.; KILINC, N. Weapon selection using the AHP and TOPSIS methods under fuzzy environment. Expert Systems with Applications, v. 36, n. 4, May 2009.

DAL BÓ, G. NODARI, C.; H.; OLEA, P, M.; DORION, E. Inovação em Serviços na Indústria Manufatureira: Os Casos Randon e White Martins, Revista INGEPRO - Inovação, Gestão e Produção, São Paulo, v. 2, n. 3, p. 93-104, mar. 2010.

DELUCA, M. A. M.; GONÇALO, C. R.; CASTRO, D., JR.; PEREIRA, M. F Capacidades de Inovação em Serviços: Um Estudo nos Supermercados em Santa Catarina. Revista Ibero Americana de Estratégia, v. 16, n. 1, 2017. 
FREITAS, A. S. FILARDI, F.; LOTT, A, C, O.; BRAGA, D. Inovação Aberta nas Empresas Brasileiras: Uma Análise da Produção Acadêmica no Período de 2003 a 2016. Revista Íbero-Americana de estratégia, v. 16, n. 03, p. 2238, 2017.

FUCK, M. P.; VILHA, A. M. Inovação Tecnológica: da definição à ação. Contemporâneos: Revista de Artes e Humanidades, n. 9, p. 1-21, abr. 2012.

GONZALEZ, I. V. D. P.; CAMPOS, F. C. Proposta de modelo conceitual de formação de estratégia de negócio a partir da integração da aprendizagem organizacional e a gestão da inovação. Gestão \& Planejamento, Salvador, v. 16, n. 3, p. 473-493, 2015

GONÇALVEZ, F. L. P.; SUGAHARA, C. R. Inovação de produto, processo, organizacional e de marketing nas indústrias brasileiras. In:ENCONTRO DE INICIAÇÃO CIENTÍFICA, 20., Campinas. Anais [...]. Campinas: PUC Campinas, 2015.

IBGE - INSTITUTO BRASILEIRO DE GEOGRAFIA E ESTATÍSTICA. Serviços. Rio de Janeiro. 2017. Disponível em: https://brasilemsintese.ibge.gov.br/servicos.html. Acesso em 10 abr. 2018.

INSTITUTO BRASILEIRO DE GEOGRAFIA E ESTATÍSTICA (IBGE). Pesquisa Anual de Serviços. Rio de Janeiro, v. 16, p.1-82, 2014. Disponível em: http://biblioteca.ibge.gov.br/visualizacao/periodicos/150/pas_2014_v16.pdf. Acesso em: 10 abr. 2018.

INSTITUTO BRASILEIRO DE GEOGRAFIA E ESTATÍSTICA (IBGE). Pesquisa de Inovação Tecnológica (PINTEC). Rio de Janeiro, 227 p., 2011. Disponível em:

http://www.pintec.ibge.gov.br/downloads/pintec2011\%20publicacao\%20completa.pd. Acesso em: 10 abr. 2018.

JAKUBCIONIS, M.; CARLSSON, J. Estimation of European Union service sector space cooling potential. Elsevier, v. 113, p. 223-231, 2018.

JOHNSTON, A.; HUGGINS, R. Regional Growth Dynamics in the Service Sector: The Determinants of Employment Change in UK Regions, 1971-2005. Growth and change, v. 49, n. 1, p. 71-96, 2018.

KINOSHITA, K. F. O perfil da inovação em serviços no Brasil: Uma comparação internacional. 2013.91 p. Dissertação (Mestrado em Administração) - Universidade Nove de Julho, São Paulo, 2013.

KON, A. Ecossistemas de inovação: a natureza da inovação em serviços. Revista de Administração, Contabilidade e Economia da FUNDACE, v. 7, n. 1, p. 14-27, 2016.

MARTINS, V. M. C.; MARTINS, R. S. M.; SIEDENBERG, D. R.; GRIEBELER, M. P. D Gestão da inovação em cooperativa de grande porte do setor de fabricação de alimentos. Revista de Administração, v. 14, n. 25, p. 57-71, 2016.

OECD. Proposta de Diretrizes para Coleta e Interpretação de Dados sobre Inovação Tecnológica. OCDE, Finep. 2004. Disponível em: http://www.finep.gov.br/images/a-finep/biblioteca/manual_de_oslo.pdf. Acesso em: 10 abr. 2018.

OECD. Diretrizes para Coleta e Interpretação de Dados sobre Inovação. 3. ed. OCDE, Finep, 1997. Disponível em: https://www.finep.gov.br/images/apoio-e-financiamento/manualoslo.pdf. Acesso em: 10 abr. 2018.

PACHECO, E. R. M. Mapeamento do fomento à inovação tecnológica no Brasil. 2010.153 p. Dissertação (Mestrado em Tecnologia)-Centro Federal de Educação Tecnológica Celso Suckow da Fonseca, Rio de Janeiro, 2010. 
PINHEIRO, R. G. ROMEIRO, M. O.; FARIA, A. C.; SANTOS, I. C.; SCUCUGLIA, R. Inovação no setor de serviços em São Caetano do Sul (SP): Mensuração e oportunidades de desenvolvimento local. Desenvolvimento em Questão, ljuí, v. 13, n. 29, p. 57-89, 2015.

RUFFATTO, J.; PAULI, J.; FERRÃO, A. R. Influência do estilo de liderança na motivação e conflitos interpessoais em empresas familiares. Revista de Administração FACES Journal, Belo Horizonte, v. 16, n. 1, p. 29-44, 2016.

SANTOS, M. Economia Espacial: Críticas e Alternativas. 2. ed. São Paulo: Edusp, Editora da Universidade de São Paulo, 2003.

SAATY, T. L. How to make a decision: the analytic hierarchy process. European journal of operational research, v. 48, n. 1, p. 9-26, 1990.

SAATY, T. L. Método de Análise Hierárquica. Tradução e Revisão por Wainer da Silveira e Silva. São Paulo: McGraw-Hill, 1991.

SAATY, T. L. Decision making with the analytic hierarchy process. International journal of services sciences, v. 1, n. 1, p. 83-98, 2008.

SAATY, T. L.; SHIH, H. S. Structures in decision making: On the subjective geometry of hierarchies and networks. European Journal of Operational Research, v. 199, n. 3, p. 867-872, 2009.

SELLITTO, M. A.; BORCHARDT, M.; PEREIRA, G.; GOMES, L. Environmental performance assessment of a provider of logistical services in an industrial supply chain. Theoretical Foundations of Chemical Engineering, v. 46, n. 6, p. 691-703, 2012.

SERVIÇO BRASILEIRO DE APOIO ÀS MICRO E PEQUENAS EMPRESAS. Participação das Micro e Pequenas Empresas na Economia Brasileira. [2014]. Disponível em: https://www.sebrae.com.br/Sebrae/Portal\%20Sebrae/Estudos\%20e\%20Pesquisas/Participacao\%20das\%20m icro\%20e\%20pequenas\%20empresas.pdf. Acesso em: 30 dez. 2017.

SILVA, T. C.; BURGER, F. Aprendizagem organizacional e inovação: contribuições da Gestão do Conhecimento para propulsionar um ambiente corporativo focado em aprendizagem e inovação. Navus, Revista de Gestão e Tecnologia, v. 8, n. 1, p. 07-19, 2018.

SCHUMPETER, J. A. A Teoria do Desenvolvimento Econômico: uma investigação sobre lucro, capital, crédito, juro e o ciclo econômico. Rio de Janeiro: Nova Cultural, 1982.

TIGRE, P.B. Gestão da Inovaç̧ão: a economia da tecnologia no Brasil. 7. ed. Rio de Janeira: Editora Elsevier, 2006.

TIDD, J.; BESSANT, J. Gestão da Inovação. 5. ed. Porto Alegre: Editora Bookman, 2015.

VARGAS, E. R. A Dinâmica da Inovação em serviços: O Caso dos Serviços Hospitalares no Brasil e na

França, 2006. 282 p. Tese (Doutorado em Administração) - Universidade Federal do Rio Grande do Sul, Porto Alegre, 2006.

VARGAS, E. R. Relação Entre Estratégia e Inovação em Serviços: Análise de Casos no Setor Hospitalar. Revista Organizações \& Sociedade, Salvador, v. 14, n. 40, p. 17-27, jan./mar. 2007.

WOLF, I. As 8 dimensões da gestão da inovação eficiente. Ninho blog, Goiânia, 22 de nov. 2015. Disponível em: https://ninho.biz/blog/organizacao-empresarial/as-8-dimensoes-da-gestao-da-inovacao-eficiente/.

Acesso em: 10 abr. 2018. 